\title{
Metabolite Profiling of Human Amniotic Fluid by Hyphenated Nuclear Magnetic Resonance Spectroscopy
}

\author{
Gonçalo Graça, ${ }^{\dagger}$ Iola F. Duarte, ${ }^{\dagger}$ Brian J. Goodfellow, ${ }^{\dagger}$ Isabel M. Carreira, ${ }^{*}$ Ana Bela Couceiro, ${ }^{\S}$ \\ Maria do Rosário Domingues," Manfred Spraul, ${ }^{\perp}$ Li-Hong Tseng, ${ }^{\perp}$ and Ana M. Gil*,†
}

\begin{abstract}
CICECO-Department of Chemistry, and Mass Spectrometry Centre, Department of Chemistry, Campus Universitário de Santiago, University of Aveiro, 3810-193 Aveiro, Portugal, Bruker Biospin GmbH, Silberstreifen, D76287 Rheinstetten, Germany, Cytogenetics Laboratory and Center of Neurosciences and Cellular Biology, Faculty of Medicine, University of Coimbra, 3001-401 Coimbra, Portugal, and Maternidade Bissaya Barreto, Centro Hospitalar de Coimbra, Coimbra, Portugal
\end{abstract}

The metabolic profiling of human amniotic fluid (HAF) is of potential interest for the diagnosis of disorders in the mother or the fetus. In order to build a comprehensive metabolite database for HAF, hyphenated NMR has been used, for the first time, for systematic HAF profiling. Experiments were carried out using reverse-phase (RP) and ion-exchange liquid chromatography (LC), in order to detect less and more polar compounds, respectively. RP-LC conditions achieved good separation of amino acids, some sugars, and xanthines. Subsequent NMR and MS analysis enabled the rapid identification of $30 \mathrm{com}-$ pounds, including 3-methyl-2-oxovalerate and 4-aminohippurate identified in HAF for the first time, to our knowledge. Under ion-exchange $\mathrm{LC}$ conditions, a different set of $\mathbf{3 0}$ compounds was detected, including sugars, organic acids, several derivatives of organic acids, and amino acids. In this experiment, five compounds were identified for the first time in HAF: D-xylitol, amino acid derivatives ( $\mathrm{N}$-acetylalanine, $\mathrm{N}$-acetylglycine, 2-oxoleucine), and isovalerate. The nonendogenous nature of some metabolites (caffeine, paraxanthine, D-xylitol, sorbitol) is discussed. Hyphenated NMR has allowed the rapid detection of $\sim 60$ metabolites in HAF, some of which are not detectable by standard NMR due to low abundance $(\mu \mathrm{M})$ and signal overlap thus enabling an extended metabolite database to be built for HAF.

Proton NMR spectroscopy has become a routine tool for fast, comprehensive characterization of complex mixtures, ${ }^{1}$ including biofluids, ${ }^{2-5}$ liquid foods, ${ }^{6-8}$ and plant extracts. ${ }^{9-13}$ Such detailed characterization is particularly useful in metabonomic studies that

* To whom correspondence should be addressed. Tel.: +351 234 370707. Fax: +351 234 370084. E-mail: agil@ua.pt.

${ }^{\dagger}$ CICECO-Department of Chemistry, University of Aveiro.

* University of Coimbra.

$\$$ Centro Hospitalar de Coimbra.

"Mass Spectrometry Centre, Department of Chemistry, University of Aveiro.

${ }^{\perp}$ Bruker Biospin GmbH.

(1) Fan, T. W. M. Prog. Nucl. Magn. Reson. Spectrosc. 1996, 28, 161-219.

(2) Sean, X. P. Biomed. Chromatogr. 2000, 14, 430-441.

(3) Corcoran, O.; Spraul, M. Drug Discovery Today 2003, 8, 624-631. aim to understand the effects of perturbations on living systems through the measurement of changes in their metabolome. ${ }^{1} \mathrm{H}$ NMR spectroscopy enables the identification of many tens or hundreds of compounds simultaneously, is noninvasive, and requires little or no sample preparation. The use of autosampling methods for large numbers of samples to enable statistical validation of the data is also common place. However, when complex mixtures are analyzed, preferably without any previous sample simplification like extraction or separation, the issue of spectral complexity is a serious hindrance due to extensive signal overlap. The desired level of compound identification depends on the problem addressed, and often, partial assignment of the spectra for a selection of compounds (or family of compounds) will suffice. Also, in classification studies where reproducible sample differences are detected and validated by a range of increasingly sophisticated chemometrics methods, the full assignment of these changes may not always be necessary. In the case of biological fluids and tissues, the quest is often to find specific compounds that may be used as markers for some kind of system perturbation, e.g., disease, diet, and medication. Often, the nature of these markers is not known in advance, and hence, further unveiling of spectral overlap may be of crucial importance. The development of hyphenated NMR methods, with the coupling of an HPLC step immediately prior to NMR analysis (LC-NMR) enables compound separation and analysis to be carried out

(4) Dear, G. J.; Plumb, R. S.; Sweatman, B. C.; Parry, P. S.; Roberts, A. D.; Lindon, J. C.; Nicholson, J. K.; Ismail, I. M. J. Chromatogr., B: Biomed. Sci. Appl. 2000, 748, 295-309.

(5) Lindon, J. C.; Nicholson, J. K.; Wilson, I. D. J. Chromatogr., B: Biomed. Sci. Appl. 2000, 748, 233-258.

(6) Gil, A. M.; Duarte, I. F.; Godejohann, M.; Braumann, U.; Maraschin, M.; Spraul, M. Anal. Chim. Acta 2003, 488, 35-51.

(7) Le Gall, G.; Colquhoun, I. J.; Davis, A. L.; Collins, G. J.; Verhoeyen, M. E. J. Agric. Food Chem. 2003, 51, 2447-2456.

(8) Anatoli, P.; Sobolev, A. S. R. L. Magn. Reson. Chem. 2003, 41, 237-245.

(9) Jean-Luc, Wolfender.; Emerson F., Queiroz.; Hostettmann, K. Magn. Reson. Chem. 2005, 43, 697-709.

(10) Vassiliki, Exarchou.; Manfred, Krucker.; Teris, A.; van, Beek.; Jacques, Vervoort.; Ioannis P., Gerothanassis.; Albert, K. Magn. Reson. Chem. 2005, 43, 681-687.

(11) Jean-Luc, Wolfender.; Hostettmann, K. N. K. Phytochem. Anal. 2001, 12, $2-22$.

(12) Jaroszewski, J. Planta Med. 2005, 691, 700.

(13) Jaroszewski, J. Planta Med. 2005, 795, 802. 
quickly. ${ }^{14}$ Further advances, driven mostly by the need to improve sensitivity, include cryoprobe technology, ${ }^{15}$ coupling with mass spectrometry (MS) (LC-NMR/MS), ${ }^{3,16}$ solid-phase extraction (SPE) of hydrophobic compounds, ${ }^{16}$ and several LC developments such as ultraperformance liquid chromatography. ${ }^{17}$ In addition, increasingly sophisticated data analysis methodologies are emerging to aid and speed up the analysis and interpretation of hyphenated NMR data. ${ }^{18,19}$

Hyphenated NMR methods have shown promise in fields such as toxicology, drug metabolism, and biomarker identification. ${ }^{5,20}$ Some examples include the detection of metabolites of ibuprofen and acetaminophen in urine, ${ }^{15,21}$ identification of biomarkers for kidney xenobiotic toxicity, ${ }^{22}$ and characterization of lipoproteins in human blood serum. ${ }^{23}$ The majority of hyphenated NMR studies on natural or biological mixtures have involved the use of reverse-phase (RP) LC columns, and this approach may be of limited use if the composition in terms of more polar metabolites is to be assessed. In these cases, ion-exchange or hydrophilic interaction chromatography ${ }^{4,24}$ LC columns need to be employed.

In this work, the extent to which hyphenated NMR can add to the compositional information on human amniotic fluid (HAF), compared to 1D and 2D NMR spectroscopy, is evaluated for both polar and nonpolar compounds. The choice of this biological fluid is justified by its potential for the understanding and diagnosis of several perturbations of the health of fetuses and their mothers. Early attempts to correlate ${ }^{1} \mathrm{H}$ NMR spectra of HAF with the occurrence of disorders such as spina bifida and chromosome-derived disorders in the fetus and preeclampsia or gestational diabetes in the mother have been carried out; ${ }^{25}$ however, extended spectral assignment and statistical validation are required. A recent $1 \mathrm{D}$ and $2 \mathrm{D}$ NMR study has enabled the identification of up to 50 metabolites in $\mathrm{HAF} ;{ }^{26}$ however, many minor compounds were detected for which no assignment could be achieved. The use of hyphenated NMR methods in tandem with cryotechnology is shown here to aid the identification of some of these metabolites in HAF and the usefulness of both reverse-phase and ionic-exchange LC experiments is compared and discussed. A more complete database of metabolites has thus been built for HAF, against

(14) Griffiths, L. Anal. Chem. 1995, 67, 4091-4095.

(15) Spraul, M.; Freund, A. S.; Nast, R. E.; Withers, R. S.; Maas, W. E.; Corcoran, O. Anal. Chem. 2003, 75, 1536-1541.

(16) Godejohann, M.; Tseng, L.-H.; Braumann, U.; Fuchser, J.; Spraul, M. J. Chromatogr., A 2004, 1058, 191-196.

(17) Wilson, I. D.; Nicholson, J. K.; Castro-Perez, J.; Granger, J. H.; Johnson, K. A.; Smith, B. W.; Plumb, R. S. J. Proteome Res. 2005, 4, 591-598.

(18) Cloarec, O.; Campbell, A.; Tseng, L.h.; Braumann, U.; Spraul, M.; Scarfe, G.; Weaver, R.; Nicholson, J. K. Anal. Chem. 2007, 79, 3304-3311.

(19) Shen, H.; Airiau, C. Y.; Brereton, R. G. Chemom. Intell. Lab. Syst. 2002, $62,61-78$.

(20) Lindon, J. C.; Holmes, E.; Nicholson, J. K. Pharm. Res. 2006, 23, 10751088.

(21) Spraul, M.; Hofmann, M.; Dvortsak, P.; Nicholson, J. K.; Wilson, I. D. Anal. Chem. 1993, 65, 327-330.

(22) Foxall, P. J. D.; Lenz, E. M.; Lindon, J. C.; Neild, G. H.; Wilson, I. D.; Nicholson, J. K. Ther. Drug Monit. 1996, 18, 498-505.

(23) Daykin, C. A.; Corcoran, O.; Hansen, S. H.; Bjornsdottir, I.; Cornett, C.; Connor, S. C.; Lindon, J. C.; Nicholson, J. K. Anal. Chem. 2001, 73, 10841090.

(24) Godejohann, M. J. Chromatogr., A 2007, 1156, 87-93.

(25) Bock, J. L. Clin Chem 1994, 40, 56-61.

(26) Graça, G.; Duarte, I. F.; Goodfellow, B. J.; Barros, A. S.; Carreira, I. M.; Couceiro, A. B.; Spraul, M.; Gil, A. M. Anal. Chem. 2007, 79, 8367-8375. which compositional changes may be detected and measured in metabolic studies of fetuses and mother disorders.

\section{EXPERIMENTAL SECTION}

Samples. Amniotic fluid samples were obtained from healthy pregnant women with ages of $>35$ and at a gestation time of 16-17 weeks, under ethical committee approval (Comissão Ética para a Saúde, Maternidade Bissaya Barreto, Centro Hospitalar de Coimbra). The samples of HAF (15-20 mL) were centrifuged (177.4g, $22{ }^{\circ} \mathrm{C}, 10 \mathrm{~min}$ ) and the supernatants collected and frozen at -70 ${ }^{\circ} \mathrm{C}$ for up to 4 months, until NMR analysis. All samples were ultrafiltered through $3 \mathrm{kDa}$ cutoff Nanosep $3 \mathrm{~K}$ Omega centrifuge membrane filters (Pall Corp.). The resulting $M_{\mathrm{w}}<3 \mathrm{kDa}$ fractions were freeze-dried, reconstituted in $\mathrm{D}_{2} \mathrm{O}$ to 10 times the initial concentration, centrifuged, and the supernatants used for analysis.

1D ${ }^{1} \mathrm{H}$ NMR of whole HAF. The $1 \mathrm{D}^{1} \mathrm{H}$ NMR spectrum of an HAF sample, prepared as described above, was recorded on a Bruker Avance spectrometer with a cryo-probe, operating at 600.13 $\mathrm{MHz}$ for ${ }^{1} \mathrm{H}$. A "noesypr $1 \mathrm{~d}$ " pulse sequence $\left(\mathrm{RD}-90^{\circ}-t_{1}-90^{\circ}-\right.$ $t_{\mathrm{m}}-90^{\circ}$-acquire) was used, with a $13.20 \mu \mathrm{s} 90^{\circ}$ pulse, $100 \mathrm{~ms}$ mixing time $\left(t_{\mathrm{m}}\right), 4 \mu \mathrm{s} t_{1}$, and $4 \mathrm{~s}$ relaxation delay and 32 transients were collected into $32 \mathrm{~K}$ data points for a $8865.25 \mathrm{~Hz}$ spectral width. Water presaturation was performed at $2816.62 \mathrm{~Hz}$ during the relaxation delay and mixing time. After exponential multiplication of the free induction decay (FID) with a $0.3 \mathrm{~Hz}$ line-broadening function, Fourier transformation was performed and the spectrum manually phased, automatically baseline corrected, and chemical shifts referenced internally to the anomeric proton of $\alpha$-D-glucose at $5.23 \mathrm{ppm}$.

Hyphenated NMR Methods. Instrumentation. The HPLC equipment consisted of either an Agilent 1100 or Agilent 1200 solvent delivery system with a quaternary pump, solvent degasser, autosampler, DAD (Agilent, Waldbronn), and column oven. The Agilent 1100 system was connected through a BPSU-36/2 interface (Bruker BioSpin, Rheinstetten, Germany) to an NMR Avance spectrometer, working at $500.17 \mathrm{MHz}$ for proton, with a $3 \mathrm{~mm}$ LCSEI probe head (60 $\mu \mathrm{L}$ active volume) and an Esquire 3000 electrospray ion trap mass spectrometer (Bruker Daltonics, Bremen, Germany); the Agilent 1200 system was connected to an Avance $600 \mathrm{MHz}$ spectrometer with cryoprobe (Bruker BioSpin). To confirm some of the results (repetition of 1D and 2D NMR on selected LC fractions), an Agilent 1100 system connected to a DRX-500 NMR spectrometer was used, with a ${ }^{1} \mathrm{H}-{ }^{13} \mathrm{C}$ inverse detection flow probe.

LC-NMR/MS and LC-SPE-NMR for Detection of Less-Polar Compounds. For detecting less-polar compounds, samples were injected onto a Phenomenex RP C18 column at $35{ }^{\circ} \mathrm{C}$, using a mobile phase $\left(\mathrm{pH}\right.$ 2.0) consisting of a mixture of solution $\mathrm{A}\left(\mathrm{D}_{2} \mathrm{O}\right.$ $+0.1 \%$ formic acid deuterated to $90 \%$ ) and solution B (acetonitrile $+0.1 \%$ formic acid deuterated to $90 \%$ ), with the following gradient program: $10-30 \%$ B from 0 to $40 \mathrm{~min}$ and then from 30 to $90 \% \mathrm{~B}$ from 40 to $45 \mathrm{~min}$. Sample volumes were $100 \mu \mathrm{L}$, and DAD detection was set at $200-210$ and $254-280 \mathrm{~nm} .{ }^{1} \mathrm{H}$ NMR spectra were recorded at $500.17 \mathrm{MHz}$ using the loop-sampling method. The "lc1pncwps" pulse sequence from Bruker library with double solvent presaturation was employed, with 512, 1024, or 2048 transients (depending on the chromatographic peak intensity), 16k data points, a spectral width of $10000 \mathrm{~Hz}$, and $0.8 \mathrm{~s}$ acquisition time. Each FID was zero-filled to $32 \mathrm{k}$, multiplied by an exponential 
a)

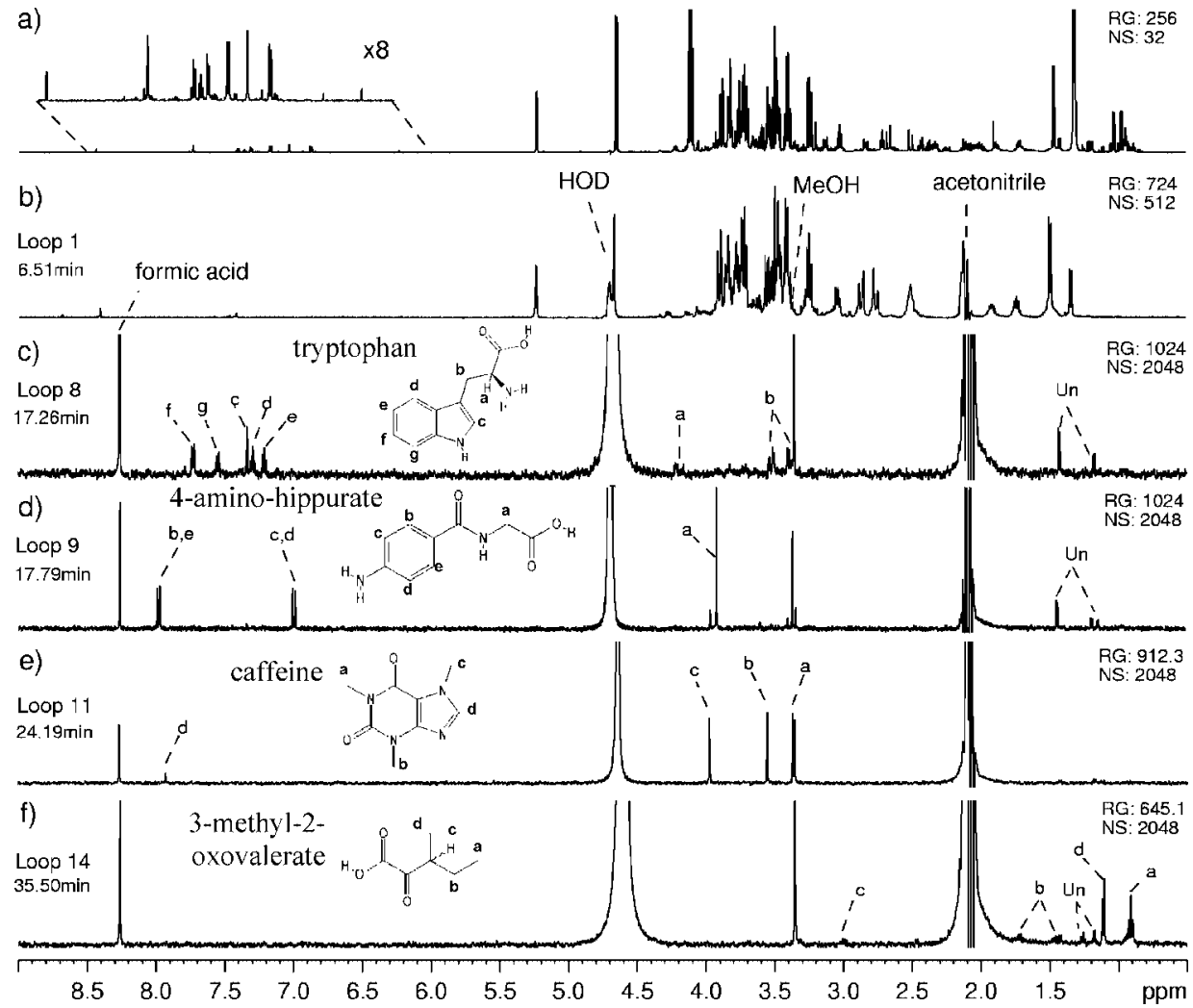

Figure 1. ${ }^{1} \mathrm{H}$ NMR spectra of (a) whole HAF fraction with $M_{\mathrm{w}}<3 \mathrm{kDa}$ and selected fractions resulting from its analysis by RP-C18 LC-NMR/ MS: (b) loop 1, several coeluting compounds at RT < $10 \mathrm{~min}$; (c) loop 8, containing tryptophan; (d) loop 9, containing 4-aminohippurate; (e) loop 11, containing caffeine; (f) loop 14, containing 3-methyl-2-oxovalerate. Loop numbers correspond to those shown in Figure S1. Un., unassigned peak; RG, receiver gain; NS, number of transients.

function (1 Hz line broadening), manually phased, and baseline corrected. For selected fractions, ${ }^{1} \mathrm{H}-{ }^{1} \mathrm{H}$ TOCSY spectra were recorded. MS and $\mathrm{MS}^{n}$ data were acquired during the chromatographic run in positive mode and during fraction transfer in both positive and negative modes, using the mass range $50-1000 \mathrm{~m} / z$. A spray voltage of $3500 \mathrm{~V}$ was applied; $\mathrm{N}_{2}$ was used as sheath gas at $60 \mathrm{psi}, 11 \mathrm{~L} / \mathrm{min}$ and at $350^{\circ} \mathrm{C}$ as dry gas. For LC-SPE-NMR, the injection volume was $20 \mu \mathrm{L}$ and all other chromatographic conditions were the same. Selected peaks were trapped into SPE cartridges and extracted with either methanol- $d_{4}$ or acetonitrile before transfer through a Prospekt interface into the cryoprobe head with cryofit (30 $\mu$ L active volume). ${ }^{1} \mathrm{H}$ NMR spectra were recorded at $600.13 \mathrm{MHz}$ using the parameters described above.

LC-NMR and LC-MS for Detection of More-Polar Compounds. For detection of polar compounds, samples were injected onto a ION300 $300 \times 7.8 \mathrm{~mm}$ cation-exchange column, with a particle size of $5.0 \mu \mathrm{m}$ (Interaction Chromatography Inc., San Francisco, CA) specific for organic acids, alcohols, and sugars, at a temperature of $22^{\circ} \mathrm{C}$, under isocratic conditions. For LC-NMR, $100 \mu \mathrm{L}$ injection volumes and a mobile phase composed of $2.5 \mathrm{mM} \mathrm{H}_{2} \mathrm{SO}_{4}$ in $100 \% \mathrm{D}_{2} \mathrm{O}(\mathrm{pH} 2.4)$ were used, whereas for LC-MS, the volume injected was $20 \mu \mathrm{L}$ and $\mathrm{D}_{2} \mathrm{O}$ was replaced by water in the mobile phase. ${ }^{1} \mathrm{H}$ NMR spectra were recorded at $600.13 \mathrm{MHz}$ (with a cryoprobe and a $120 \mu \mathrm{L}$ active volume) using the time-sliced stopflow method. The "lc1pnf2" sequence from the Bruker pulse program library was used, with water presaturation at $2817.22 \mathrm{~Hz}$, a flow of $0.3 \mathrm{~mL} / \mathrm{min}$, and a total run time of $70 \mathrm{~min}$. Every $30 \mathrm{~s}$, the flow was stopped and a 1D spectrum collected with 64 transients, $32 \mathrm{k}$ data points, spectral width of $12019 \mathrm{~Hz}$, and $1.36 \mathrm{~s}$ acquisition time. Each FID was multiplied by an exponential function ( $1 \mathrm{~Hz}$ line broadening), manually phased, and baseline corrected. Mass spectra were collected in both positive and negative modes, in the mass range of $90-1000 \mathrm{~m} / z$, with auto $\mathrm{MS}^{n}$.

\section{RESULTS AND DISCUSSION}

Identification of Less-Polar Compounds in HAF by Reverse-Phase LC Hyphenated to NMR and MS. The LC and MS chromatograms obtained for HAF fractions with $M_{\mathrm{w}}<3 \mathrm{kDa}$, run on a RP-C18 column with DAD detection at 200-210 nm (Figure S1a, Supporting Information), result from the early elution (in the first $10 \mathrm{~min}$ ) of the majority of HAF metabolites, of a polar nature, followed by elution of the more hydrophobic compounds. Several fractions were collected in loops (the numbering shown in Figure S1a relates to loop number) and stored for NMR analysis. Figure $1 \mathrm{~b}-\mathrm{f}$ shows the ${ }^{1} \mathrm{H}$ NMR spectra of some of these LC fractions, compared to the spectrum of the whole HAF sample (Figure 1a). The spectrum of loop 1, at 6.51-min retention time (RT) shows overlapping profiles of several coeluting polar molecules such as amino acids (alanine, lysine, glutamine and glutamate, threonine), organic acids (citrate and lactate), sugars and polyalcohols (glucose, myo-inositol), and others (betaine, creatine, choline). Spin systems from compounds eluting at later retention times (Figure 1c-f) present much cleaner spectral profiles, enabling detailed assignment to be carried out. 


\begin{tabular}{|c|c|c|c|c|c|}
\hline \multirow[b]{2}{*}{ loop no. RT (min) } & \multicolumn{2}{|c|}{$\operatorname{MS}(m / z)$} & \multirow[b]{2}{*}{$\delta^{1} \mathrm{H}$, ppm (multiplicity, $J$ in $\mathrm{Hz}$, assignment) } & \multirow[b]{2}{*}{ compound } & \multirow{2}{*}{$\begin{array}{c}\text { expected } \\
\text { concentration }(\mu \mathrm{M})\end{array}$} \\
\hline & MS & MS/MS & & & \\
\hline \multirow[t]{6}{*}{$1 / 6.51$} & & & $1.49\left(\mathrm{~d}, 7.3, \mathrm{CH}_{3}\right)$ & alanine & $323^{28}$ \\
\hline & $193.8^{f}$ & & $2.77\left(\mathrm{AB}, 15.3, \mathrm{CH}_{2}\right), 2.86\left(\mathrm{AB}, 15.0, \mathrm{CH}_{2}\right)$ & citrate & $345^{35}$ \\
\hline & $202.8^{f}$ & & $\begin{array}{l}3.24(\mathrm{dd}, \mathrm{H} 2), 3.40(\mathrm{t}, \mathrm{H} 4), 3.49(\mathrm{t}, \mathrm{H} 3), 3.47(\mathrm{dd}, \mathrm{H} 5) \text {, } \\
3.73\left(\mathrm{dd}, \mathrm{H}^{\prime} 6\right), 3.90(\mathrm{dd}, \mathrm{H} 6), 4.64(\mathrm{t}, \mathrm{H} 1)\end{array}$ & $\beta$-D-glucose & \\
\hline & 153.1 & & $\begin{array}{l}1.49\left(\mathrm{~m}, \gamma \mathrm{CH}_{2}\right), 1.73\left(\mathrm{~m}, \delta \mathrm{CH}_{2}\right), 1.91\left(\mathrm{~m}, \beta \mathrm{CH}_{2}\right), \\
3.03\left(\mathrm{t}, 7.5, \epsilon \mathrm{CH}_{2}\right)\end{array}$ & lysine & $202^{28}$ \\
\hline & $202.8^{f}$ & & 3.28(t, H5), 3.62(t, H4/H6), 4.06(t, 2.9, H2) & myo-inositol & $396^{36}$ \\
\hline & & & $1.33\left(\mathrm{~d}, 6.6, \gamma \mathrm{CH}_{3}\right), 4.27\left(\mathrm{ABX}, \beta \mathrm{CH}_{2}\right)$ & threonine & $156^{28}$ \\
\hline \multirow[t]{4}{*}{$2 / 7.12$} & & & $3.27\left(\mathrm{~s}, \mathrm{CH}_{3}\right)$ & betaine & $66^{36}$ \\
\hline & & & $3.05\left(\mathrm{~s}, \mathrm{CH}_{3}\right)$ & creatine & $99.8^{36}$ \\
\hline & & & $3.20\left(\mathrm{~s}, \mathrm{CH}_{3}\right), 4.06\left(\mathrm{~m}, \mathrm{CH}_{2}\right)$ & choline & $11^{28}$ \\
\hline & $90.0^{f}$ & & $1.38\left(\mathrm{~d}, \mathrm{CH}_{3}\right), 4.26(\mathrm{q}, \mathrm{CH})$ & lactate & $9800^{35}$ \\
\hline \multirow[t]{2}{*}{$4 / 9.50$} & & & $3.14\left(\mathrm{~s}, \mathrm{CH}_{3}\right)$ & creatinine & $44^{28}$ \\
\hline & 153.9 & 133.9 & $\begin{array}{l}2.14\left(\mathrm{~s}, \mathrm{SCH}_{3}\right), 2.24\left(\mathrm{~m}, \beta \mathrm{CH}_{2}\right), 2.67\left(\mathrm{t}, \gamma \mathrm{CH}_{2}\right), \\
\quad 4.01\left(\mathrm{dd}, \alpha \mathrm{CH}_{2}\right)\end{array}$ & methionine & $14^{28}$ \\
\hline \multirow[t]{3}{*}{$5 / 10.01$} & 135.9 & 88.3 & $\begin{array}{l}0.98\left(\mathrm{t}, 6.2, \delta \mathrm{CH}_{3}\right), 1.74(\mathrm{~m}, \gamma \mathrm{CH}), 1.81\left(\mathrm{~m}, \beta \mathrm{CH}_{2}\right) \text {, } \\
3.91(\mathrm{~m}, \alpha \mathrm{CH})\end{array}$ & leucine & $68^{28}$ \\
\hline & 135.9 & 88.3 & $\begin{array}{c}0.96\left(\mathrm{t}, 7.4, \delta \mathrm{CH}_{3}\right), 1.04\left(\mathrm{~d}, 7.0, \beta \mathrm{CH}_{3}\right), 1.32(\mathrm{~m}, \\
\gamma \mathrm{CH}), 1.51(\mathrm{~m}, \gamma \mathrm{CH}), 3.86(\mathrm{~d}, 3.7, \alpha \mathrm{CH})\end{array}$ & isoleucine & $29^{28}$ \\
\hline & 186.8 & 166.8 & $\begin{array}{l}\text { 3.11( } \mathrm{ABX}, \beta \mathrm{CH}), 3.25\left(\mathrm{ABX}, \beta \mathrm{CH}^{\prime}\right), 4.10(\mathrm{dd}, \alpha \mathrm{CH}) \text {, } \\
6.91(\mathrm{~d}, 8.5 \text {, ring } \mathrm{H} 3), 7.21(\mathrm{~d}, 8.5 \text {, ring } \mathrm{H} 2)\end{array}$ & tyrosine & $51^{35}$ \\
\hline $6 / 12.11$ & $169.866 .8^{f}$ & 122.0 & $\begin{array}{l}\text { 3.16(ABX, } \beta \mathrm{CH}), 3.32\left(\mathrm{ABX}, \beta \mathrm{CH}^{\prime}\right), 4.12(\mathrm{dd}, \alpha \mathrm{CH}) \text {, } \\
7.34(\mathrm{~m} \text {, ring } \mathrm{H} 6), 7.39(\mathrm{~m} \text {, ring } \mathrm{H} 4), 7.44(\mathrm{~m} \text {, ring } \\
\mathrm{H} 3 / \mathrm{H} 5)\end{array}$ & phenylalanine & $53^{28}$ \\
\hline $7 / 14.27$ & 183.0 & & $3.50\left(\mathrm{~s}, \mathrm{CH}_{3}\right), 3.95\left(\mathrm{~s}, \mathrm{CH}_{3}\right), 7.93(\mathrm{~s}, \mathrm{CH})$ & paraxanthine $^{b}$ & \\
\hline $8 / 17.26$ & $209.9202 .8^{f}$ & 190.8 & $\begin{array}{l}\text { 3.38(ABX, } \beta \mathrm{CH}), 3.52\left(\mathrm{ABX}, \beta \mathrm{CH}^{\prime}\right), 4.21(\mathrm{ABX}, \\
\alpha \mathrm{CH}), 7.21(\mathrm{t}, \text { ring } \mathrm{H} 5 / \mathrm{H} 6), 7.29(\mathrm{t}, \text { ring } \mathrm{H} 5 / \mathrm{H} 6) \text {, } \\
7.33(\mathrm{~s}, \text { ring } \mathrm{H} 2), 7.55(\mathrm{~d} \text {, ring } \mathrm{H} 7), 7.72(\mathrm{~d} \text {, ring } \\
\mathrm{H} 4)\end{array}$ & tryptophan $^{b}$ & $10^{28}$ \\
\hline $14 / 35.50$ & & & $\begin{array}{l}0.91\left(\mathrm{t}, 7.4, \mathrm{CH}_{3}\right), 1.11\left(\mathrm{~d}, 7.0, \mathrm{CH}_{3}\right), 1.45(\mathrm{~m}, \mathrm{CH}) \\
\quad 1.72\left(\mathrm{~m}, \mathrm{CH}^{\prime}\right), 3.00(\mathrm{~m}, \mathrm{CH})\end{array}$ & 3-methyl-2-oxovalerate ${ }^{b}$ & \\
\hline
\end{tabular}

loop no./RT (min)

$2 / 7.12$
$3 / 7.93$
$4 / 9.50$
$5 / 10.01$
$9 / 17.79$
$12 / 29.09$

unassigned spin systems $\delta^{1} \mathrm{H}$, ppm (multiplicity)

$3.30(\mathrm{~s}) ; 3.23(\mathrm{~s}) ; 3.60(\mathrm{~s}) ; 4.48(\mathrm{~s}) ; 7.37(\mathrm{~s}), 7.43(\mathrm{~s})$ $1.15(\mathrm{~d}) ; 1.25(\mathrm{~d}) ; 1.10(\mathrm{~m})$

$1.14(\mathrm{~d}), 3.45(\mathrm{~m}), 3.53(\mathrm{dd}) ; 3.88(\mathrm{~d})$

$1.14(\mathrm{~d}) ; 1.18(\mathrm{t}) ; 3.14(\mathrm{~s}) ; 3.65(\mathrm{~s})$ $3.33(\mathrm{~s}) ; 3.91(\mathrm{~s}) ; 3.97(\mathrm{~s})$

$3.19(\mathrm{~s}) ; 3.66(\mathrm{~s}) ; 4.19(\mathrm{~s}) ; 7.37(\mathrm{t}), 7.58(\mathrm{~m})$

\section{signals from contaminants $\delta^{1} \mathrm{H}$, ppm (multiplicity)}

3.56(dd), 3.65(dd), $3.77(\mathrm{~m})$

$3.35(\mathrm{~s})$

$0.93(\mathrm{t}) ; 0.95(\mathrm{~s}) ; 1.14(\mathrm{~s})$;

$1.18(\mathrm{~d}) ; 1.43(\mathrm{~d}) ; 1.26(\mathrm{t})$ glycerol (membrane filter) methanol (system) unidentified (system) unidentified (system)

${ }^{a}$ Loop numbers are those used in Figure S1. Expected concentration values (for 2nd trimester of pregnancy) are shown in the last column. ${ }^{b}$ Newly found by NMR. ${ }^{c}$ Tentative assignment, no MS information available. MS and MS/MS $m / z$ values correspond to $[\mathrm{M}+\mathrm{D}]^{+}$adducts except those in footnotes d-f. ${ }^{d}$ Values correspond to $[\mathrm{M}-\mathrm{D}] .{ }^{e}$ Values correspond to $[\mathrm{M}+\mathrm{H}]^{+} .{ }^{f}$ Values correspond to $[\mathrm{M}+\mathrm{Na}]^{+}$.

Table 1lists all the assigned spin systems and MS information resulting from the reverse-phase LC-NMR/MS (the superscript "b" identifies compounds newly detected by NMR in HAF), as well as the main unassigned spin systems. Some contaminant compounds found to be present in the LC-NMR system or in the membrane filters used to prepare the $M_{\mathrm{w}}<3 \mathrm{kDa} \mathrm{HAF}$ fraction are also listed. A total of 30 compounds were assigned in this experiment, using previous work ${ }^{26}$ a compound database search (mainly in Brukers BioSpin BBiorefcode 2.0.0 standard compound database), and, whenever possible, the recording of spectra of standard compounds at the $\mathrm{pH}$ of the experiment ( $\mathrm{pH}$ 2). 4-Aminohippurate and 3-methyl-2-oxovalerate (Figure 1d,f) have been identified for the first time, to our knowledge, in HAF. Mannose, caffeine, paraxanthine, tryptophan, and hippurate, previously detected in HAF by several other analytical methods, ${ }^{27-30}$ have been identified here for the first time by NMR, in one single experiment.

Caffeine and paraxanthine (1,3,7-trimethylxanthine and 1,7dimethylxanthine, respectively) are not usually endogenous in 


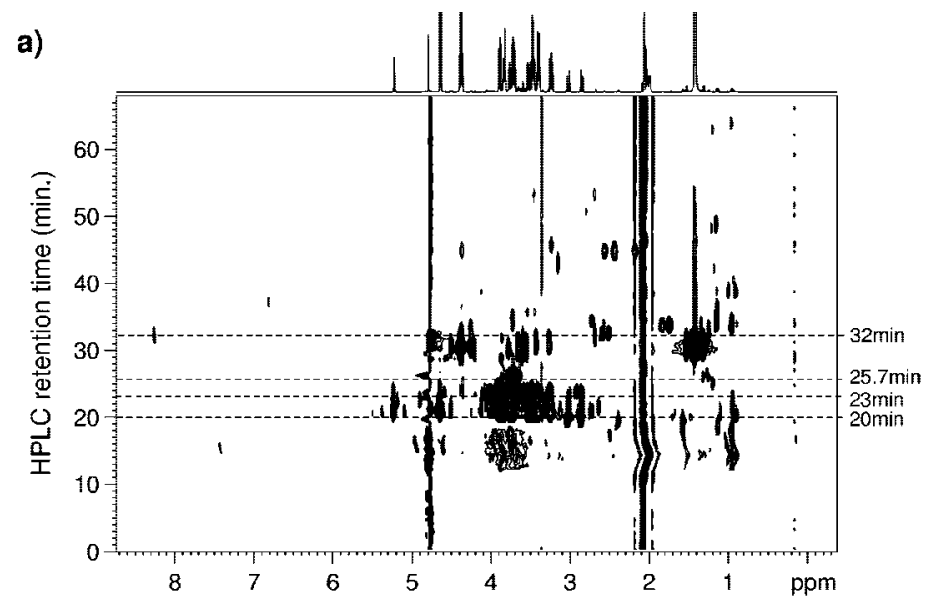

b)
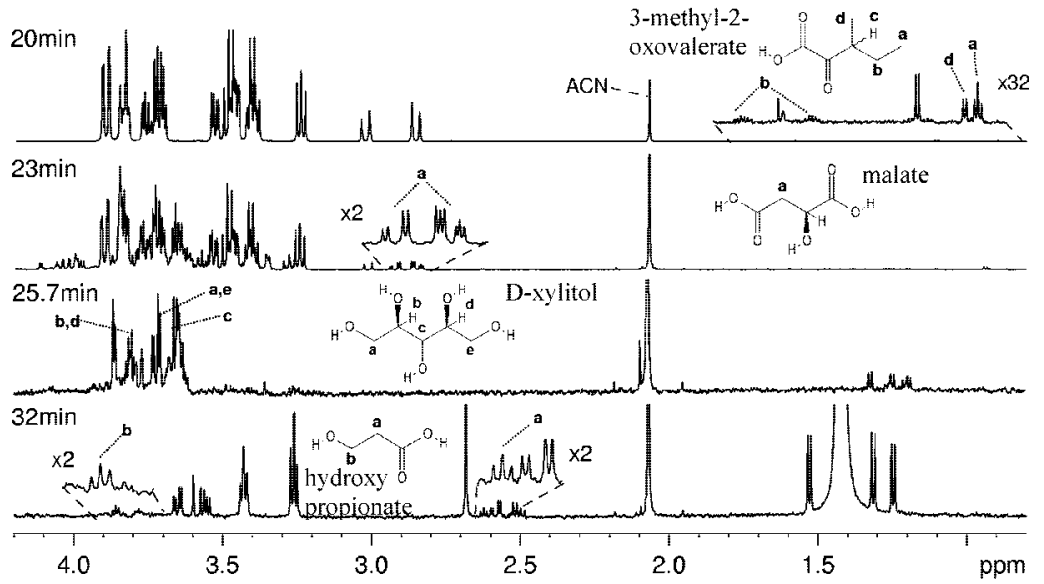

Figure 2. (a) LC-NMR 2D chromatogram recorded with an ION300 LC-NMR experiment of a 10-fold concentrated HAF fraction with $M_{\mathrm{w}}<3$ $\mathrm{kDa}$ (the apparent distortion at earlier RTs is due to empty volume effects) and (b) selected lines taken from (a), for retention times of 20 (containing 3-methyl-2-oxovalerate), 23 (containing malate), 25.7 (containing D-xylitol), and 32 min (containing hydroxypropionate). RG, 724; NS: 64 for all lines; Un, unassigned peak.

humans and paraxanthine is the main metabolite of caffeine. The presence of these compounds in HAF most probably arises from maternal ingestion of caffeine-containing beverages, e.g., coffee, and consequent fetal excretion into the amniotic fluid. This was indeed confirmed by consultation of the medical records of the donors. The detection and quantitation of these metabolites in $\mathrm{HAF}$ is of considerable interest due to their possible adverse effects on mother's and fetus' health. These compounds have been first detected in HAF by gas chromatography and mass spectrometry, ${ }^{29}$ and a more recent capillary electrophoresis study ${ }^{30}$ had reported the presence of a xanthine compound in HAF although no comment was made as to its origin. LC-NMR methods may, in principle, be employed to quantify these metabolites, as long as an adequate reference compound and finely controlled experimental conditions are used throughout the duration of the experiment, in order to ensure fixed and constant flux values. This is, however, beyond the scope of the present work.

Tryptophan is a known component of HAF, although its detection by ${ }^{1} \mathrm{H}$ NMR had not been reported before, most probably

(27) Ng, K. J.; Andresen, B. D.; Bianchine, J. R.; Iams, J. D.; O’Shaugnessy, R. W.; Stempel, L. E.; Zuspan, F. P. J. Chromatogr., B: Biomed. Sci. Appl. 1982, 228, 43-50.

(28) Tuma, P.; Samcova, E.; Andelova, K. J. Chromatogr., B 2006, 839, 12-18.

(29) Sommer, K. R.; Hill, R. M.; Horning, M. G. Res. Commun. Chem. Pathol. Pharmacol. 1975, 12 (3), 583-95.

(30) Stewart, C. J.; Iles, R. K.; Perrett, D. Electrophoresis 2001, 22, 1136-1142. due to its low concentration. Indeed, expected concentrations lie in the $4.7-18.0 \mu \mathrm{M}$ range, as determined by capillary electrophoresis for the same maternal age and gestation times considered here. $^{28}$ Unlike hippurate, which is ubiquitous in human urine ${ }^{15}$ and has been detected in HAF before, ${ }^{31}$ endogenous 4-aminohippurate has not, to our knowledge, been observed in HAF. This compound is sometimes employed for measurement of amniotic fluid volume; ${ }^{32}$ however, this procedure was not carried out here and it may be concluded that the compound detected is of an endogenous origin.

LC-SPE-cryo-NMR was attempted for the peaks eluting after 10 min RT (Supporting Information, Figure S1), in order to characterize other nonpolar metabolites. However, the corresponding ${ }^{1} \mathrm{H}$ NMR spectra (data not shown) did not add any further metabolite information, due to the poor compound retention in the SPE cartridges employed.

Identification of More-Polar Compounds in HAF by IonExchange LC Hyphenated to NMR. The LC and MS chromatograms obtained for the analysis of a $M_{\mathrm{w}}<3 \mathrm{kDa} \mathrm{HAF}$ fraction on a cation-exchange column are shown in Figure S1b (Supporting Information). The intensity of the MS signal was relatively low, compared to that obtained for the RP experiment, reflecting poor ionization of the polar compounds separated by the cationexchange column used here. 


\begin{tabular}{|c|c|c|c|c|c|}
\hline \multirow[b]{2}{*}{$\mathrm{RT}(\min )$} & \multicolumn{2}{|c|}{$\operatorname{MS}(m / z)$} & \multirow[b]{2}{*}{$\delta^{1} \mathrm{H}$, ppm (multiplicity, $J$ in $\mathrm{Hz}$, assignment) } & \multirow[b]{2}{*}{ compound } & \multirow{2}{*}{$\begin{array}{c}\text { expected } \\
\text { concentration }(\end{array}$} \\
\hline & MS & MS/MS & & & \\
\hline 14.0 & & & $3.2(\mathrm{~s}), 3.3(\mathrm{~s}), 3.6-4.0$ (broad profile) & methoxylated oligosaccharide (U2) ${ }^{\mathrm{a}}$ & \\
\hline 16.0 & 407.0 & 214.5 & $3.6-3.9,4.35,4.99(\mathrm{~d}), 7.40(\mathrm{~s})$ & pentose & \\
\hline 19.0 & & & $0.94\left(\mathrm{~d}, 7.0, \gamma \mathrm{CH}_{3}\right)$ & isovalerate $\mathrm{a}^{\mathrm{a}, \mathrm{b}}$ & \\
\hline 19.5 & & & $2.85\left(\mathrm{AB}, \mathrm{CH}_{2}, 15.8\right), 3.03\left(\mathrm{AB}, 15.8, \mathrm{CH}_{2}\right)$ & citrate & $345^{35}$ \\
\hline & & & $2.38\left(\mathrm{~s}, \mathrm{CH}_{3}\right)$ & pyruvate & \\
\hline & & & $1.58\left(\mathrm{~s}, \mathrm{CH}_{3}\right)$ & pyruvate (hydrate form) & \\
\hline 20.0 & & & $\begin{array}{l}0.89\left(\mathrm{t}, 7.5, \delta \mathrm{CH}_{3}\right), 1.09\left(\mathrm{~d}, 6.8, \beta^{\prime} \mathrm{CH}_{3}\right), 1.46(\mathrm{~m}, \\
\gamma \mathrm{CH}), 1.68\left(\mathrm{~m}, \gamma^{\prime} \mathrm{CH}\right), 2.92(\mathrm{~m}, \beta \mathrm{CH})\end{array}$ & 3-methyl-2-oxovalerate ${ }^{b}$ & \\
\hline 20.5 & 202.8 & & $\begin{array}{l}3.41(\mathrm{t}, \mathrm{H} 4), 3.52(\mathrm{dd}, \mathrm{H} 2), 3.70(\mathrm{t}, \mathrm{H} 3), 3.76(\mathrm{dd}, \mathrm{H} 6) \text {, } \\
3.83(\mathrm{~m}, \mathrm{H} 5), 5.23(\mathrm{~d}, \mathrm{H} 1)\end{array}$ & $\alpha$-D-glucose & $2510^{35}$ \\
\hline & 202.8 & & $\begin{array}{l}3.24(\mathrm{dd}, \mathrm{H} 2), 3.40(\mathrm{t}, \mathrm{H} 4), 3.49(\mathrm{t}, \mathrm{H} 3), 3.47(\mathrm{dd}, \mathrm{H} 5) \text {, } \\
3.73\left(\mathrm{dd}, \mathrm{H}^{\prime} 6\right), 3.90(\mathrm{dd}, \mathrm{H} 6), 4.64(\mathrm{t}, \mathrm{H} 1)\end{array}$ & $\beta$-D-glucose & \\
\hline & 324.9 & $162.8^{d}$ & $\begin{array}{l}3.12(\mathrm{dd}), 3.29(\mathrm{~m}), 3.36(\mathrm{~m}), 3.59(\mathrm{~m}), 3.66(\mathrm{~m}) \\
3.96(\mathrm{dd}), 4.01(\mathrm{dd}), 4.12(\mathrm{~m}), 4.25(\mathrm{~d}), 4.32(\mathrm{t}) \\
4.50(\mathrm{~d}), 5.50(\mathrm{~d})\end{array}$ & hexose disaccharide $^{b}$ & \\
\hline 21.0 & & & $0.94\left(\mathrm{~d}, 6.8, \gamma \mathrm{CH}_{3}\right), 2.09(\mathrm{~m}, \beta \mathrm{CH}) 2.64(\mathrm{~d}, \alpha \mathrm{CH})$ & 2-oxoleucine ${ }^{b}$ & \\
\hline 21.5 & 202.8 & & $3.26(\mathrm{t}, \mathrm{H} 5), 3.61(\mathrm{dd}, \mathrm{H} 4 / \mathrm{H} 6), 4.05(\mathrm{t}, \mathrm{H} 2)$ & myo-inositol & $396^{36}$ \\
\hline 22.0 & 202.8 & & $\begin{array}{l}3.56(\mathrm{t}, \mathrm{H} 3), 3.64(\mathrm{~m}, \mathrm{H} 3 / \mathrm{H} 4), 3.93(\mathrm{~m}, \mathrm{H} 2), 4.90(\mathrm{~d}, \\
\left.\mathrm{H}^{\prime} 6\right), 5.18(\mathrm{~d}, \mathrm{H} 6)\end{array}$ & D-mannose $\mathrm{e}^{b}$ & \\
\hline 22.5 & 202.8 & & $\begin{array}{l}3.57(\mathrm{~m}, \mathrm{H} 1), 3.80(\mathrm{~d}, \mathrm{H} 6), 3.99(\mathrm{~m}, \mathrm{H} 4), 4.03(\mathrm{dd}, \\
\text { H5), } 4.11(\mathrm{~d}, \mathrm{H} 3)\end{array}$ & $\mathrm{D}$-fructose ${ }^{b}$ & \\
\hline 23.5 & & & $2.85(\mathrm{ABX}, \beta \mathrm{CH}), 2.92\left(\mathrm{ABX}, \beta \mathrm{CH}^{\prime}\right), 4.57(\mathrm{dd}, \alpha \mathrm{CH})$ & malate & \\
\hline 24.5 & $182.8^{d}$ & $164.8^{d} 65.9^{d}$ & $\begin{array}{l}3.63(\mathrm{~m}, \mathrm{H} 1 / \mathrm{H} 4 / \mathrm{H} 6), 3.73(\mathrm{~d}, \mathrm{H} 6), 3.76(\mathrm{~m}, \mathrm{H} 3) \\
3.82(\mathrm{~d}, \mathrm{H} 1), 3.84(\mathrm{~m}, \mathrm{H} 2 / \mathrm{H} 5)\end{array}$ & sorbitol $^{b}$ & \\
\hline 25.7 & & & 3.65(m, H3), $3.72(\mathrm{dd}, \mathrm{H} 1 / \mathrm{H} 5), 3.80(\mathrm{~m}, \mathrm{H} 2 / \mathrm{H} 4)$ & D-xylitol ${ }^{b}$ & \\
\hline 30.5 & & & $1.42\left(\mathrm{~d}, 7.1, \mathrm{CH}_{3}\right), 4.38(\mathrm{q}, 7.0, \mathrm{CH})$ & lactate & $9800^{35}$ \\
\hline 30.8 & & & $3.26\left(\mathrm{t}, 6.6, \mathrm{CH}_{2}\right), 3.43\left(\mathrm{t}, 6.6, \mathrm{CH}_{2}\right)$ & taurine & $83^{35}$ \\
\hline 31.5 & & & $2.62\left(\mathrm{t}, 6.0, \mathrm{CH}_{2}\right), 3.86\left(\mathrm{t}, 5.9, \mathrm{CH}_{2}\right)$ & hydroxypropionate $^{b}$ & $9.5-27^{33}$ \\
\hline 32.0 & & & $2.68\left(\mathrm{~s}, \mathrm{CH}_{2}\right)$ & succinate & \\
\hline & & & $8.45(\mathrm{~s}, \mathrm{CH})$ & formate & \\
\hline 32.5 & & & $\begin{array}{l}1.25\left(\mathrm{~d}, 6.4, \gamma \mathrm{CH}_{3}\right), 2.51(\mathrm{ABX}, \beta \mathrm{CH}), 2.59(\mathrm{ABX}, \\
\left.\beta \mathrm{CH}^{\prime}\right), 4.24(\mathrm{~m}, \alpha \mathrm{CH})\end{array}$ & 3-hydroxybutyrate & $120^{35}$ \\
\hline 33.5 & & & $1.34\left(\mathrm{~s}, \mathrm{CH}_{2}\right), 2.57\left(\mathrm{~s}, \mathrm{CH}_{2}\right)$ & 2-hydroxyisobutyrate & \\
\hline 33.7 & & & $\begin{array}{l}0.96\left(\mathrm{t}, 7.5, \gamma \mathrm{CH}_{3}\right), 1.74(\mathrm{~m}, \beta \mathrm{CH}), 1.84\left(\mathrm{~m}, \beta \mathrm{CH}^{\prime}\right), \\
\quad 4.25(\mathrm{~m}, \alpha \mathrm{CH})\end{array}$ & 2-hydroxybutyrate & $50^{35}$ \\
\hline 35.0 & & & $2.32\left(\mathrm{~s}, \mathrm{CH}_{3}\right)$ & acetoacetic & \\
\hline 35.5 & & & $2.09\left(\mathrm{~s}, \mathrm{CH}_{3}\right)$ & acetate & \\
\hline 37.2 & & & $6.81(\mathrm{~s}, \mathrm{CH})$ & fumarate & \\
\hline 38.5 & & & $\begin{array}{l}0.90\left(\mathrm{~d}, 6.9, \gamma \mathrm{CH}_{3}\right), 1.00\left(\mathrm{~d}, 6.9, \gamma^{\prime} \mathrm{CH}_{3}\right), 2.06(\mathrm{~m}, \\
\beta \mathrm{CH}), 4.12(\mathrm{~d}, 4.3, \alpha \mathrm{CH})\end{array}$ & 2-hydroxyisovalerate & \\
\hline 44.0 & & & $2.06\left(\mathrm{~s}, \mathrm{NCH}_{3}\right), 3.96\left(\mathrm{~s}, \alpha \mathrm{CH}_{2}\right)$ & $N$-acetylglycine ${ }^{b}$ & \\
\hline 45.0 & & & $\begin{array}{l}2.17(\mathrm{~m}, \gamma \mathrm{CH}), 2.43\left(\mathrm{~m}, \beta \mathrm{CH}_{2}\right), 2.56\left(\mathrm{~m}, \gamma \mathrm{CH}^{\prime}\right), \\
\quad 4.37(\mathrm{dd}, \alpha \mathrm{CH})\end{array}$ & pyroglutamate $^{\mathrm{a}, \mathrm{b}}$ & $19-50^{33}$ \\
\hline 46.0 & & & $3.23\left(\mathrm{~s}, \mathrm{CH}_{3}\right)$ & acetylcholine ${ }^{b}$ & \\
\hline 46.5 & & & $1.41\left(\mathrm{~d}, 7.3, \mathrm{CH}_{3}\right), 2.03\left(\mathrm{~s}, \mathrm{NCH}_{3}\right)$ & $N$-acetylalanine ${ }^{b}$ & \\
\hline 53.5 & & & $2.69\left(\mathrm{t}, 7.0, \mathrm{CH}_{2}\right), 3.45\left(\mathrm{t}, 7.1, \mathrm{CH}_{2}\right)$ & 2-oxoglutarate ${ }^{c}$ & \\
\hline
\end{tabular}

unassigned spin systems

\begin{tabular}{|c|c|c|c|c|c|}
\hline \multirow[b]{2}{*}{$\mathrm{RT}(\min )$} & \multirow[b]{2}{*}{$\delta^{1} \mathrm{H}, \mathrm{ppm}$ (multiplicity) } & & \multirow[b]{2}{*}{ RT (min) } & \multirow[b]{2}{*}{$\delta^{1} \mathrm{H}, \mathrm{ppm}$ (multiplicity) } \\
\hline & & $\overline{\mathrm{RT}}(\min )$ & $\delta^{1} \mathrm{H}, \mathrm{ppm}$ (multiplicity) & & \\
\hline 12.5 & $1.0(\mathrm{~m}), 1.6(\mathrm{~d}), 3.9(\mathrm{~s})(\mathrm{U} 1)$ & 25.5 & $3.62(\mathrm{~m}), 3.68(\mathrm{~m}), 3.78(\mathrm{dd})$ & 35.8 & $3.44(\mathrm{dd}), 3.54(\mathrm{dd})$ \\
\hline 15.0 & $3.91(\mathrm{~s})$ & & $3.56(\mathrm{dd}), 4.35(\mathrm{~d})$ & 40.5 & $0.93(\mathrm{~d}), 3.74(\mathrm{t})$ \\
\hline \multirow[t]{2}{*}{16.0} & $3.20(\mathrm{~s}), 3.33(\mathrm{~s})$ & 25.8 & $1.26(\mathrm{~d}), 1.32(\mathrm{~d})$ & 40.8 & $2.46(\mathrm{~s})$ \\
\hline & $3.77(\mathrm{~m}), 3.97(\mathrm{~d}), 4.99(\mathrm{~m}), 7.46(\mathrm{~s})(\mathrm{U} 3)$ & 26.5 & $1.27(\mathrm{~d}), 1.43(\mathrm{~s})$ & 42.5 & $1.18(\mathrm{t})$ \\
\hline 16.5 & $2.50(\mathrm{~d}), 2.75(\mathrm{~m})$ & 28.8 & $3.86(\mathrm{t}), 4.54(\mathrm{~s}), 4.58(\mathrm{~s})$ & 43.0 & $3.15(\mathrm{~s})$ \\
\hline \multirow{2}{*}{18.0} & $0.95(d)$ & 29.5 & $3.60(\mathrm{~s})$ & 43.5 & $1.10(\mathrm{t})$ \\
\hline & $1.13(\mathrm{~d})$ & 30.0 & $4.21(\mathrm{~s})$ & 48.0 & $1.22(\mathrm{~s})$ \\
\hline 20.3 & $2.73(\mathrm{dd}), 2.88(\mathrm{dd})$ & 35.5 & $1.14(\mathrm{~d}, 7.1), 2.72(\mathrm{~m}), 3.72(\mathrm{~d}, 6.2)$ & 49.0 & $1.15(\mathrm{~d})$ \\
\hline 23.5 & $3.65(\mathrm{~m})$ & & $3.67(\mathrm{~s})$ & 50.5 & $2.80(\mathrm{~s})$ \\
\hline \multirow[t]{2}{*}{24.5} & $1.19(\mathrm{~d})$ & 36.0 & $2.20(\mathrm{~s})$ & 63.0 & 1.20 (d) \\
\hline & & & & 64.0 & 0.96 (d) \\
\hline
\end{tabular}

${ }^{a}$ Expected concentration values (for 2nd trimester pregnancy) are shown in the last column. ${ }^{b}$ Newly found by NMR. ${ }^{c}$ Tentative assignment. $\mathrm{MS}$ and MS/MS $m / z$ values correspond to $[\mathrm{M}+\mathrm{Na}]^{+}$adducts. ${ }^{d}$ Values corresponding to $[\mathrm{M}+\mathrm{H}]^{+}$.

Figure 2a shows the corresponding pseudo-two-dimensional LC-NMR chromatogram where each row is the $1 \mathrm{D}{ }^{1} \mathrm{H}$ NMR spectrum corresponding to each RT of the chromatographic experiment. The large spread of signals in this plot shows that separation of a large number of compounds was achieved. This follows preliminary results obtained for HAF, at lower field strength (500 MHz) using a noncryoprobe, which led to the identification, for the first time, of malic acid in HAF. ${ }^{26}$ Indeed, the improved resolution and sensitivity of the experimental conditions used here have enabled the detection of a greater 


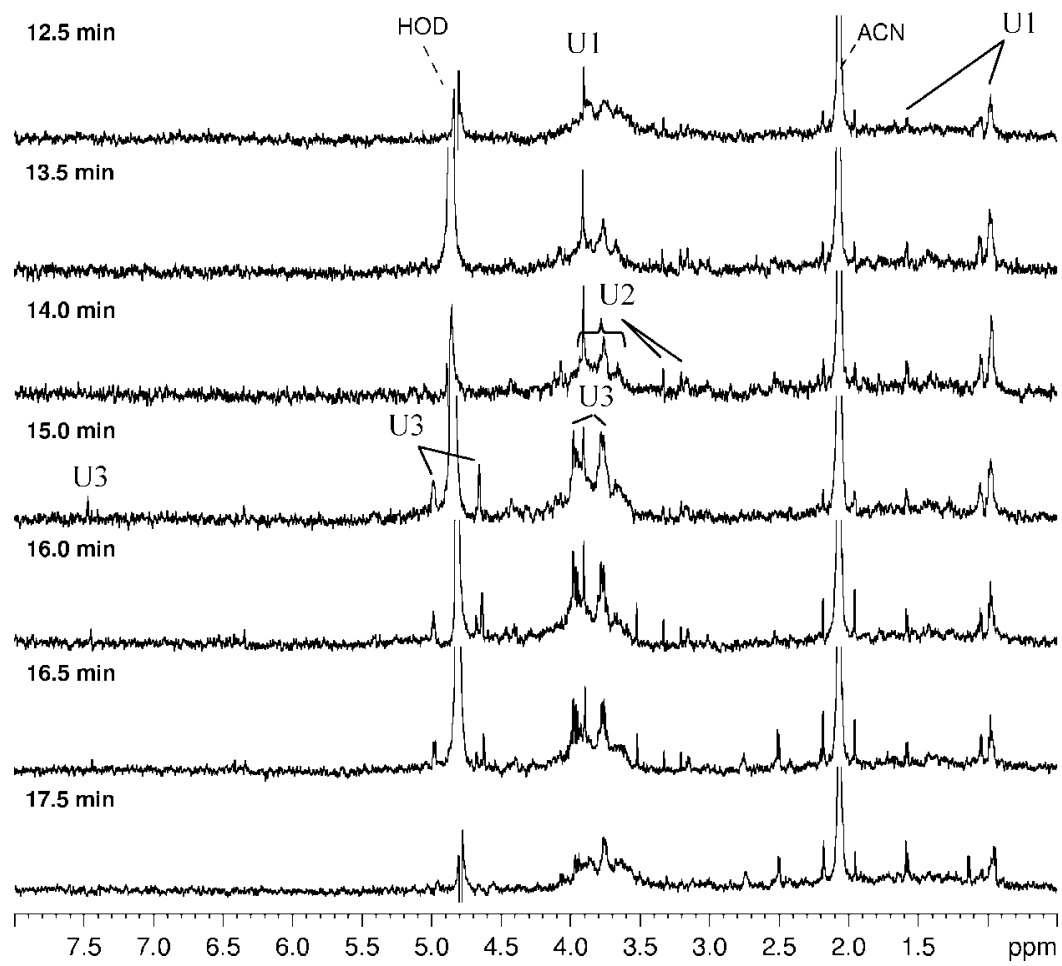

Figure 3. ${ }^{1} \mathrm{H}$ NMR spectra taken from the LC-NMR chromatogram in Figure 2, for retention times between 12 and 18 min. (The spectra were reprocessed with a $2 \mathrm{~Hz}$ line broadening and recalibrated to the ACN peak.) RG, 724; NS, 64 for all lines.

number of compounds in HAF. Table 2 shows that just over 30 compounds have been identified, mainly comprising sugars and organic acids, together with several derivatives of both organic acids and amino acids (again, the superscript "b" identifies compounds newly detected by NMR in HAF). Some of the compounds assigned (pyroglutamate, hydroxypropionate, D-mannose, D-fructose, sorbitol) had been previously found in HAF in several studies, ${ }^{28,33,34}$ and a further five compounds were identified in HAF here for the first time, to our knowledge. These comprise D-xylitol, the amino acid derivatives $N$-acetylalanine, $N$-acetylglycine, and 2-oxoleucine, and isovalerate. The spectra of selected fractions (Figure $2 \mathrm{~b}$ ) show the relatively low signal intensity of some of the compounds identified.

In addition, previous tentative assignments based on NMR alone ${ }^{26}$ were confirmed by the results obtained here, namely, for myo-inositol, 3-hydroxybutyrate and 2-hydroxybutyrate, and 2-hydroxyisovalerate, for which either low-intensity or incomplete spin systems are observed by $1 \mathrm{D}$ and 2D NMR. In the lower section of Table 2, a list of unidentified spin systems is shown, based on the concomitant intensity changes seen for consecutive rows (or spectra) in the plot shown in Figure 2a. Many of these are singlets and, therefore, difficult to identify by LC-NMR alone. In fact, LCMS analysis was also carried out, although in an off-line mode due to limitations in the experimental conditions available. However, as mentioned before, the poor compound ionization in both positive and negative modes prevented significant MS information to be added to the LC-NMR results.

Regarding sugars or sugar-like compounds, the newly found D-xylitol and sorbitol are, like caffeine and paraxanthine, exogenous metabolites possibly originating from the use of sweeteners or inclusion of some stone fruits (plums, berries) in the maternal diet. It is also noted that a hexose disaccharide (as shown by MS) coelutes with glucose at 20.5-min retention time (Table 2); however, further assignment was not possible at this stage. In addition, an interesting group of weaker signals resonating in the sugar region may be seen at earlier retention times (between 10 and 20 min RT in Figure 2). Interestingly, by comparing different samples, it can be observed that the exact composition of these early fractions is significantly dependent on the donor. In the case shown in Figure 3, the corresponding lines reflect the overlap of at least three different spin systems (U1, U2, U3), as confirmed by a TOCSY experiment carried out on a loop-collected LC-peak at 16 min retention time.

Further characterization of these compounds would, in principle, be possible by diffusion edited spectroscopy, ${ }^{26}$ but this was hindered by the weak signal-to-noise ratio characterizing the $10-20$ min RT region (Figure 2). The nature of $\mathrm{U} 1$ is not known at this stage, but the profiles of $\mathrm{U} 2$ and $\mathrm{U} 3$ resemble sugar-like profiles. The relatively broader profile of $\mathrm{U} 2$ and the singlets at 3.2 and $3.3 \mathrm{ppm}$ (Figure 3) may reflect a possibly methoxylated oligosaccharide. U3 shows clear resonances in the anomeric region, together with an unassigned resonance at $7.4 \mathrm{ppm}$, and MS results have identified this compound as a pentose sugar.

(31) Zambotti, F.; Blau, K.; King, G. S.; Campbell, S.; Sandler, M. Clin. Chim. Acta 1975, 61, 247-256.

(32) Kirshon, B.; Mari, G.; Moise, K. J., Jr. Obstet. Gynecol. 1990, 75, 202-205.

(33) Kumps, A.; Vamos, E.; Mardens, Y.; Abramowicz, M.; Genin, J.; Duez, P. J. Inherited Metab. Dis. 2004, 27, 567-579.

(34) Jauniaux, E.; Hempstock, J.; Teng, C.; Battaglia, F. C.; Burton, G. J. J. Clin. Endocrinol. Metab. 2005, 90 (2), 1171-1175.

(35) Lentner, C.; Limited, C.-G. Geigy scientific tables; Ciba-Geigy: Basle, Switzerland, 1981

(36) Groenen, P. M. W.; Engelke, U. F.; Wevers, R. A.; Hendriks, J. C. M.; Eskes, T. K. A. B.; Merkus, H. M. W. M.; Steegers-Theunissen, R. P. M. Eur. J. Obstet. Gynecol. Reprod. Biol. 2004, 112, 16-23. 

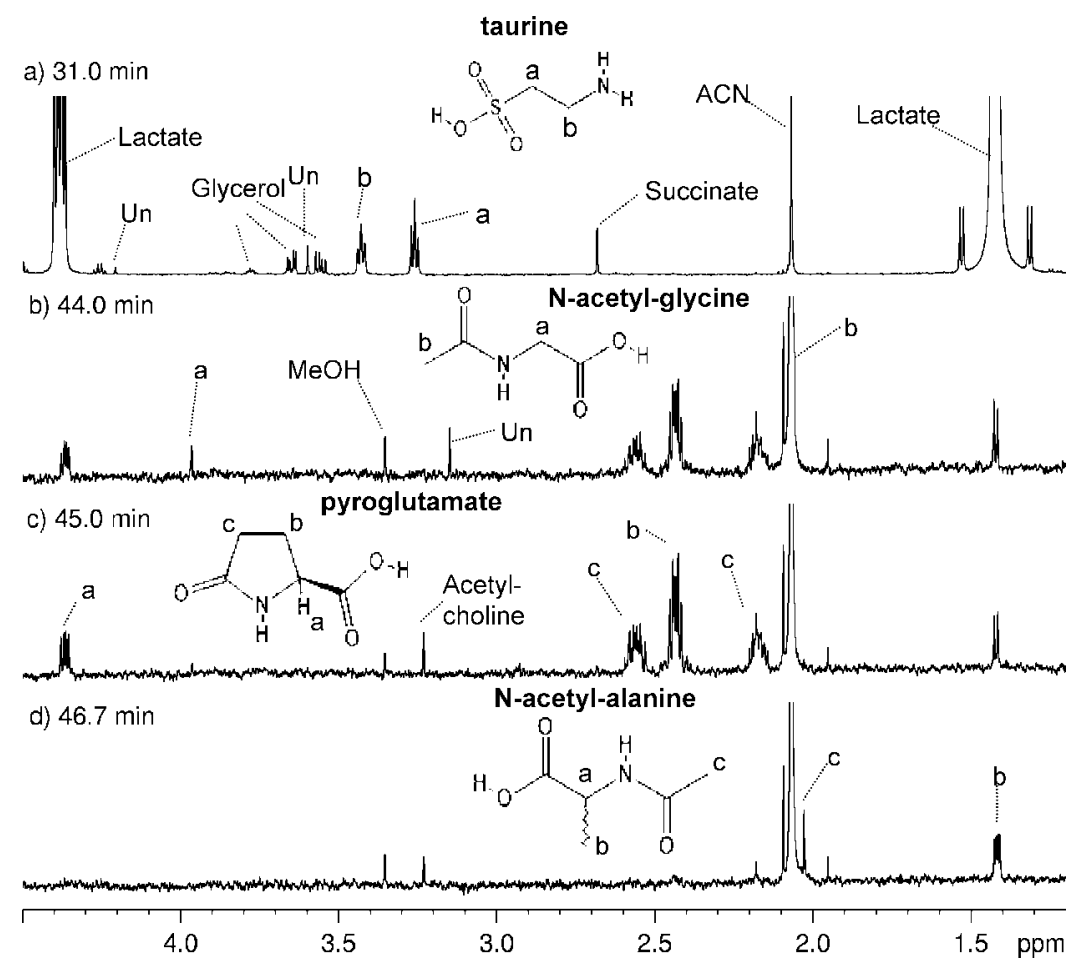

Figure 4. ${ }^{1} \mathrm{H}$ NMR spectra selected from the LC-NMR chromatogram in Figure 3 and showing the elution of some amino acid derivatives: (a) taurine, (b) $\mathrm{N}$-acetylglycine, (c) pyroglutamate, and (d) $\mathrm{N}$-acetylalanine. Structures and assignments are indicated. Some coeluting compounds are identified as well as some unassigned compounds (Un). ACN, acetonitrile present in the LC system; RG, 724; NS, 64 for all lines.

Regarding amino acids, it is interesting to note that none of the many amino acids, clearly identified before by NMR and reverse-phase LC-NMR (Table 1), is observed in the ion-exchange LC-NMR records. This is most probably due to their protonated states, occurring at $\mathrm{pH} 2$ used in this experiment, which results in high charge densities and thus leads to the high affinity of these compounds for the column employed here. Taurine and the newly detected amino acid derivatives, $N$-acetylglycine, $N$-acetylalanine, and pyroglutamate (Table 2 and Figure 4), can however be seen. In these cases, the $\mathrm{NH}_{2}$ group is replaced by a NHR group, where $\mathrm{R}$ is an acetyl or methylene group (Figure 4). This may result in a decrease in positive charge density, at $\mathrm{pH} 2$, which then would lead to lower RTs for these compounds on the column. In the case of taurine, the presence of a sulfonic group (Figure 4) determines its lower retention on the anionic column used.

\section{CONCLUSIONS}

Hyphenated NMR methods have been applied to the compositional analysis of HAF, in order to rapidly identify metabolites that could not be detected by NMR alone due to low abundance or strong signal overlap. Reverse-phase LC conditions achieved good separation of amino acids, some sugars, and xanthines, among others, and coupled NMR and MS analysis enabled the rapid identification of 30 compounds. These included 3-methyl2-oxovalerate and 4-aminohippurate, newly identified in HAF, to our knowledge, and five other compounds (including some exogenous metabolites) viewed by NMR for the first time in HAF. Under ion-exchange LC conditions, a distinct set of over 30 compounds was detected, including sugars and organic acids, but also several derivatives of organic acids and amino acids. Here, 5 compounds were identified in HAF for the first time (D-xylitol, $\mathrm{N}$-acetylalanine, $\mathrm{N}$-acetylglycine, 2-oxoleucine, isovalerate) and a further 10 compounds were newly seen by NMR. These results have shown that hyphenated NMR methods enable the simultaneous and rapid detection of many different metabolites in HAF and a more complete metabolite database (with 21 new assigned compounds) to be obtained for this biofluid, compared to the previous report based mostly on 1D and 2D NMR alone..$^{26}$ This forms the basis for metabolic studies of HAF to be carried out in order to detect biomarkers for disorders during pregnancy. Although quantitation of metabolites was not carried out here, this may be possible under hyphenated conditions, using an appropriate reference compound along with well controlled experimental conditions.

\section{ACKNOWLEDGMENT}

Funding is acknowledged from the Foundation for Science and Technology, Portugal, for research project PTDC/QUI/66523/ 2006 and grant SFRH/BD/41869/2007 for G.G. The authors also acknowledge CICECO for partial funding of this work.

\section{SUPPORTING INFORMATION AVAILABLE}

Additional information as noted in text. This material is available free of charge via the Internet at http://pubs.acs.org.

Received for review May 2, 2008. Accepted May 16, 2008. AC800907F 